\title{
Effect of cisapride on postprandial gastro-oesophageal reflux
}

\author{
R H HOLlOWAY, JOY DOWNTON, B MITCHELL, AND J DENT \\ From the Department of Medicine, Flinders Medical Centre, Bedford Park, South Australia
}

\begin{abstract}
SUMmary We studied the effect of cisapride on oesophageal motor function and postprandial gastro-oesophageal reflux in a randomised, double blind, placebo controlled crossover study. In 16 patients with symptomatic gastro-oesophageal reflux, cisapride $10 \mathrm{mg}$ orally and placebo were studied on separate days according to identical protocols. Cisapride and placebo were given 30 minutes before a standard meal. Each study day was preceded by corresponding three day oral loading of cisapride (10 $\mathrm{mg}$ tds) or placebo. Lower oesophageal sphincter pressure, oesophageal body motility and oesophageal pH were monitored for $\mathbf{3 0}$ minutes before and three hours after the meal. Plasma cisapride concentrations were measured before and after dosing on both study days. With cisapride treatment, the plasma cisapride levels ranged from $48 \cdot 1(5 \cdot 0)$ to $75.9(6 \cdot 9) \mathrm{ng} / \mathrm{ml}$. Plasma levels were undetectable during placebo treatment. Cisapride enhanced acid clearance but had no significant effect on the duration of acid exposure, the rate of reflux episodes, the pattern of lower oesophageal sphincter pressure associated with the reflux episodes, basal lower oesophageal sphincter pressure or oesophageal peristalsis. These findings do not suggest a major role for cisapride, at the dosage tested, for the control of troublesome postprandial gastro-oesophageal reflux.
\end{abstract}

Cisapride is a recently developed compound that is believed to stimulate gastrointestinal motility by enhancing release of acetylcholine from the myenteric plexus. ${ }^{-4}$ In contrast with metoclopramide and domperidone it has no antidopaminergic properties. Recent studies have shown that cisapride increases basal lower oesophageal sphincter pressure in fasting healthy subjects $\mathrm{s}^{5-\infty}$ and patients with gastro-oesophageal reflux disease suggesting it may have a role in the management of reflux disease. Gastrooesophageal reflux increases substantially after a meal and postprandial symptoms are usually the major complaint of patients with reflux disease. In this study we investigated the effect of cisapride on lower oesophageal sphincter pressure and postprandial gastro-oesophageal reflux in patients with gastro-oesophageal reflux disease.

Address for correspondence: Dr R H Holloway, Gastroenterology Unit, Royal Adelaide Hospital, North Terrace, Adelaide, South Australia 500().

Accepted for publication 4 January 1989.
Methods

STUDYGROUP

We studied 16 patients, 13 men and three women, aged 32-74 years with symptomatic gastro-oesophageal reflux. All complained of heartburn and regurgitation. Ten patients had erosive or ulcerative oesophagitis at endoscopy. Two patients with macroscopically normal oesophageal mucosa had histological evidence of gastro-oesophageal reflux."' Four patients had neither endoscopic nor histological evidence of reflux disease but had a positive Bernstein test. All patients gave written informed consent and the protocol was approved by the Ethical Review Committee of Flinders Medical Centre in November 1984.

STUDY DESIGN

The study was of randomised, double blind crossover design comparing cisapride $10 \mathrm{mg}$ po with placebo. Both cisapride and placebo were studied on separate days in each patient according to identical protocols. 
Each study day was preceded by a three day oral loading with cisapride $10 \mathrm{mg}$ tds or placebo. Between cisapride and placebo phases of the study there was a minimum washout period of three days. Gastric antisecretory agents were stopped a minimum of seven days before starting the study and any antacid use was suspended during study days.

\section{MANOMETRIC AND OESOPHAGEAL PH \\ RECORDINGS}

Oesophageal manometry was done with a multilumen assembly that incorporated a sleeve sensor at its distal end. "The catheter was positioned so that the sleeve straddled the lower oesophageal sphincter and thereby monitored sphincter pressure. A side hole $1 \mathrm{~cm}$ distal to the distal sleeve margin recorded intragastric pressure. Side holes at the level of the proximal sleeve margin, and 4,8 , and $12 \mathrm{~cm}$ more proximally recorded motor activity in the oesophageal body. A side hole in the hypopharynx monitored swallowing. Each lumen was perfused with distilled water by a pneumohydraulic capilliary infusion pump. The gastric side hole and sleeve were perfused at $0 \cdot 5$ $\mathrm{ml} / \mathrm{min}$ throughout the study. The side holes in the oesophageal body and pharynx were perfused at 0.5 $\mathrm{ml} / \mathrm{min}$ during the assessment of water swallows. At other times these latter side holes were perfused at $0.13 \mathrm{ml} / \mathrm{min}$ in order to minimise the fluid load to the patient. This lower infusion rate was selected to yield reliable recognition of the occurrence of oesophageal body and pharyngeal contractions but to minimise any possible alteration of the patterns of oesophageal acid clearance or the rate of primary or secondary peristalsis by perfusion of the manometric assembly.

Oesophageal $\mathrm{pH}$ was monitored with a Radiometer (GK2801C) pH electrode positioned $5 \mathrm{~cm}$ above the proximal margin of the lower oesophageal sphincter. The electrode was calibrated in buffers of pH 4 and 7 before and after each study. Correction for any electrode drift (in all instances $<0.4 \mathrm{pH}$ units) was made on the assumption that the drift was linear during the study. Manometric and $\mathrm{pH}$ signals were processed and recorded on an eight channel Devices M19 chart recorder. Responses to water swallows were recorded at a paper speed of $4 \mathrm{~mm} / \mathrm{s}$, at all other times the paper speed was $80 \mathrm{~mm} / \mathrm{min}$. Plasma cisapride concentrations were measured at the laboratories of Janssen Pharmaceutica (Beerse, Belgium) using high performance liquid chromatography.

STUDY PROTOCOL

Patients were studied after an overnight fast. The protocol for each study day is summarised in Fig. 1 . The patients remained recumbent on their right side except when swallowing the tablet and eating the

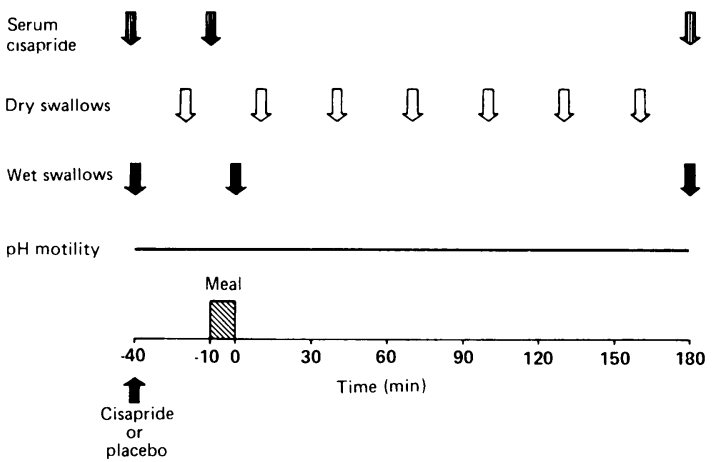

Fig. 1 Experimental protocol for each study day.

meal. Oesophageal motility and $\mathrm{pH}$ were monitored continuously for 30 minutes before and three hours after a standard meal consisting of savoury mince, mashed vegetables, ice cream and milk $(50 \%$ fat, $52 \%$ carbohydrate, $11 \%$ protein, $2595 \mathrm{~kJ})$. Oesophageal responses to water swallows ( $5 \mathrm{ml}$ bolus) taken

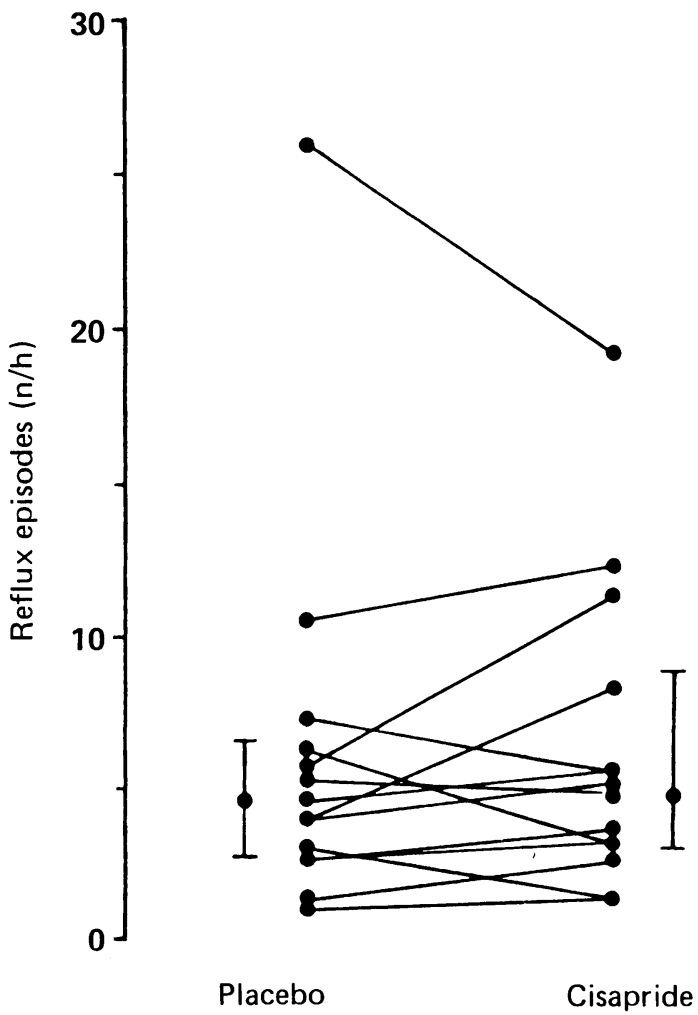

Fig. 2 Effect of cisapride on the rate of reflux episodes for three hours after a standard meal. Vertical lines indicate median values and interquartile range. 
at $20 \mathrm{~s}$ intervals were assessed before tablet administration, immediately after the meal, and at the end of the study. Blood was drawn for measurement of plasma cisapride concentration at the start of the study (before tablet administration), 30 minutes later (immediately before the meal), and at the end of the study. Sleep was not permitted during recording because of its depressant effect on reflux. ${ }^{12}$

DATA ANALYSIS

The oesophageal $\mathrm{pH}$ tracing was analysed manually to determine the time that oesophageal $\mathrm{pH}$ was $<4$. Reflux episodes were also scored individually. A reflux episode was defined either as a drop of oesophageal $\mathrm{pH}$ below 4 for at least $4 \mathrm{~s}$ or, if oesophageal $\mathrm{pH}$ was already below 4 , a further drop of at least $1 \mathrm{pH}$ unit sustained for at least $4 \mathrm{~s}$. The acid clearance time after reflux episodes was measured as time taken for oesophageal $\mathrm{pH}$ to return to 4 . Mean

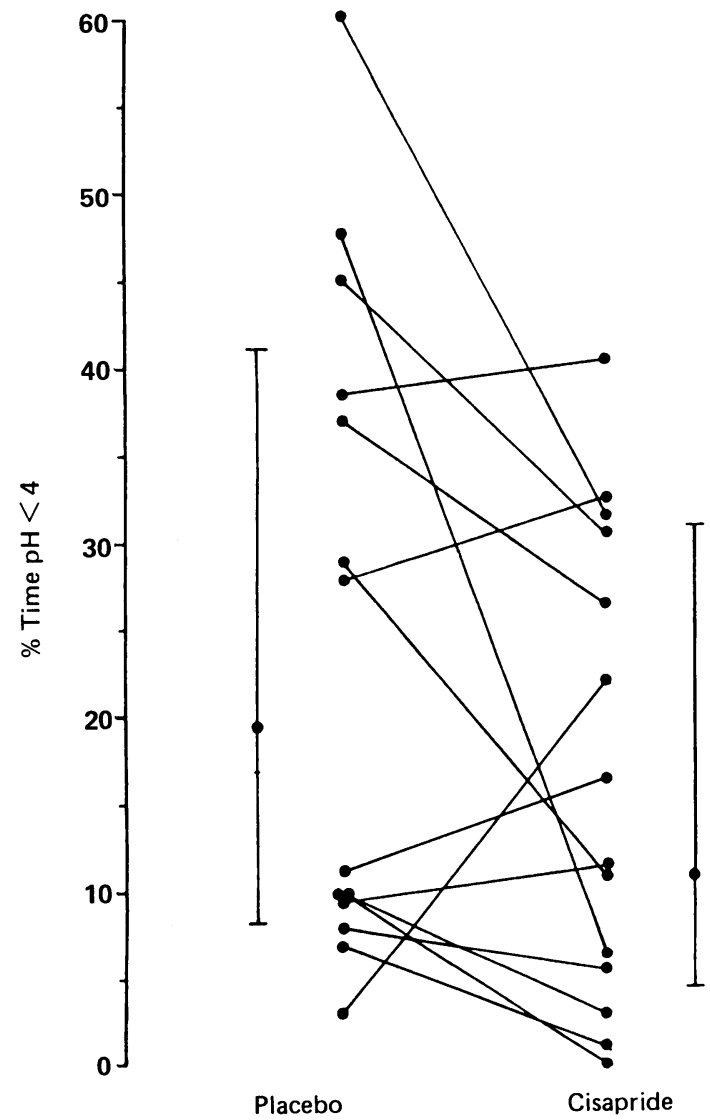

Fig. 3 Effect of cisapride on the duration of postprandial oesophageal acid exposure. Vertical lines indicate median values and interquartile range. acid clearance times were calculated for each patient for each study day and group means derived. Infrequently, oesophageal $\mathrm{pH}$ drifted downwards to below 4 during a period of several minutes. These $\mathrm{pH}$ 'drifts' were included in the analysis of the duration of oesophageal acid exposure but were not scored as reflux episodes.

The onset of the usually abrupt reduction of oesophageal $\mathrm{pH}$ associated with reflux was used as the reference for analysis of the motor events associated with reflux. For all reflux episodes the patterns of lower oesophageal sphincter, pharyngeal and oesophageal motility were measured for $30 \mathrm{~s}$ before reflux. Basal end expiratory lower oesophageal sphincter pressure was referenced to intragastric pressure and determined at 15 min intervals by taking a one min visual mean of the tracing. Overall mean values were derived for each patient for the $30 \mathrm{~min}$ before and three hours after the meal. The oesophageal body motor responses to spontaneous dry swallows were assessed on single swallows separated from preceding or subsequent swallows by at least $15 \mathrm{~s}$. The first 10 swallows in each $30 \mathrm{~min}$ interval that satisfied this criterion were used in the analysis. Because the low perfusion rate in the oesophageal leads dampens the recording of peristaltic pressure waves, contraction amplitudes during spontaneous primary peristalsis were not measured. Contraction amplitudes for peristalsis in response to water swallows were calculated as the mean amplitude for the three distal oesophageal recording sites. Oesophageal motor responses to water and dry swallows were classified as either successful or failed peristalsis. Criteria for failed peristalsis were either failure of a pressure wave $>10 \mathrm{mmHg}$ to traverse each of the oesophageal recording points, or synchronous contractions at two or more of the distal three recording sites.

Statistical analysis of the oesophageal $\mathrm{pH}$ data was done using the Wilcoxons signed-rank test. Basal lower oesophageal sphincter pressure and oesophageal contraction amplitude were analysed by analysis of variance and the Student's $t$ test for paired values. Data in the text are expressed as median values unless indicated otherwise.

\section{Results}

Technically satisfactory recordings were obtained on both study days in 14 of the 16 patients. In two patients, either the manometric or $\mathrm{pH}$ recordings (in one patient each, respectively) were technically unsatisfactory on one of the study days, and that part of the data could not be analysed.

Gastro-oesophageal reflux increased substantially after the meal on both study days. Duration of acid 


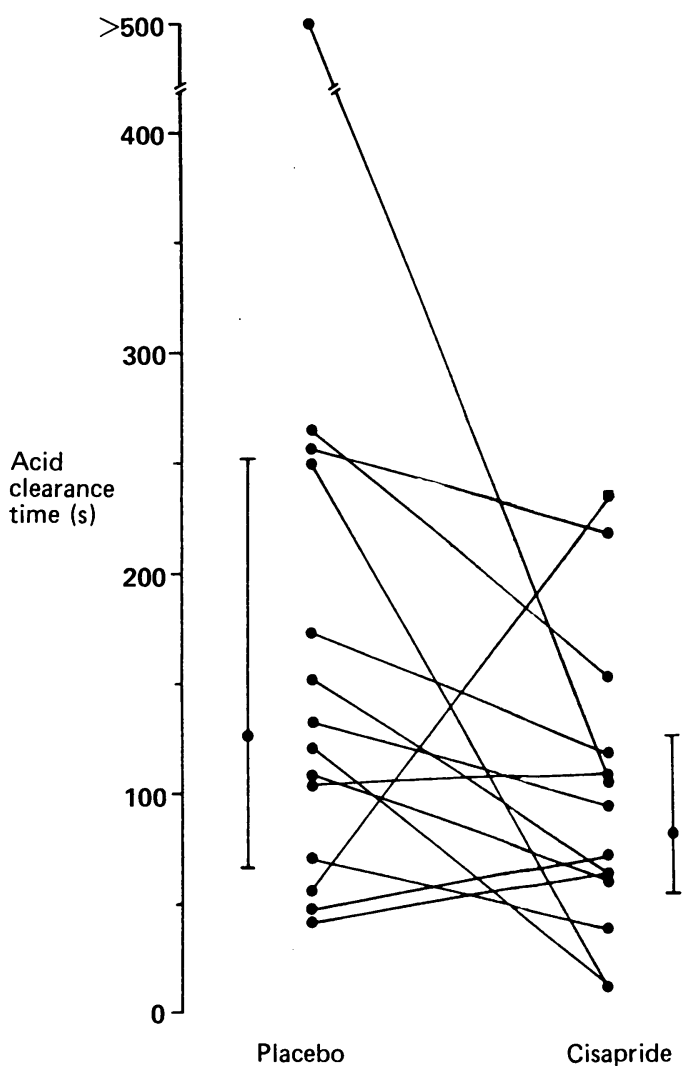

Fig. 4 Effect of cisapride on postprandial oesophageal acid clearance. Vertical lines indicate median values and interquartile range.

exposure was greatest during the first postprandial hour and decreased progressively thereafter. The rate of reflux episodes was similar for the cisapride and placebo treatments (Fig. 2). Although median percent oesophageal acid exposure time with cisapride $(11.5 \%)$ was less than that with placebo $(18 \cdot 5 \%)$, this difference was not significant (Fig. 3). Acid clearance time after cisapride (84 s), however, was significantly less than that after placebo $(126 \mathrm{~s}$, $\mathrm{p}<0 \cdot 05$ ), (Fig. 4).

Basal lower oesophageal sphincter pressure decreased immediately after the meal and then returned to and, in some patients, exceeded preprandial levels after the first hour (Fig. 5). Basal lower oesophageal sphincter pressure after cisapride, however, was not significantly different from that after placebo.

Analysis of the patterns of lower oesophageal sphincter motor function associated with the reflux episodes showed that almost $80 \%$ of episodes occurred during transient lower oesophageal sphincter

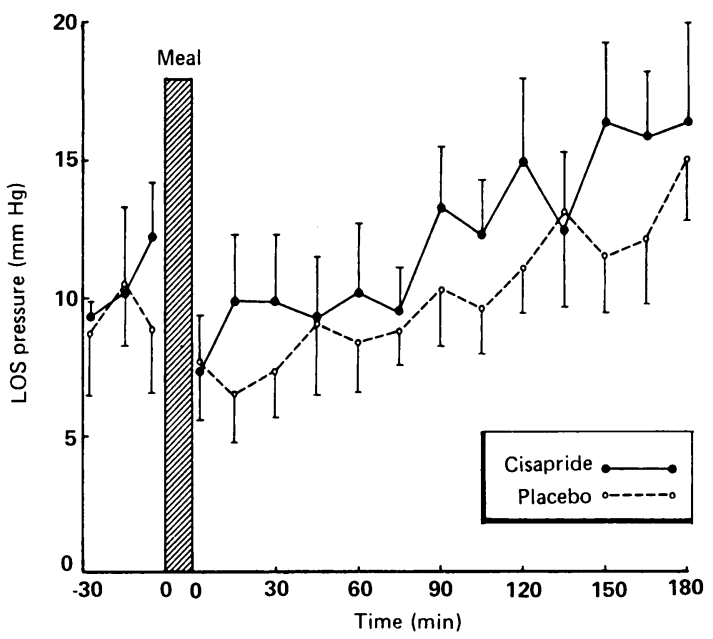

Fig. 5 Effect of cisapride on basal lower oesophageal sphincter pressure. Data are expressed as mean (SE).

relaxation (Fig. 6). A small proportion (18\%) occurred because of absent basal lower oesophageal sphincter pressure for at least $30 \mathrm{~s}$ before the onset of reflux. Occasionally $(3 \%)$ reflux occurred during large pressure transients caused by straining or deep inspiration, almost invariably associated with low basal lower oesophageal sphincter pressure $(<5$ $\mathrm{mmHg}$ ). Patients did not reflux exclusively via any one mechanism and the distribution of the three major mechanisms of reflux did not differ between cisapride and placebo treatments.

Parameters of peristalsis for the postprandial period are summarised in the Table. No significant

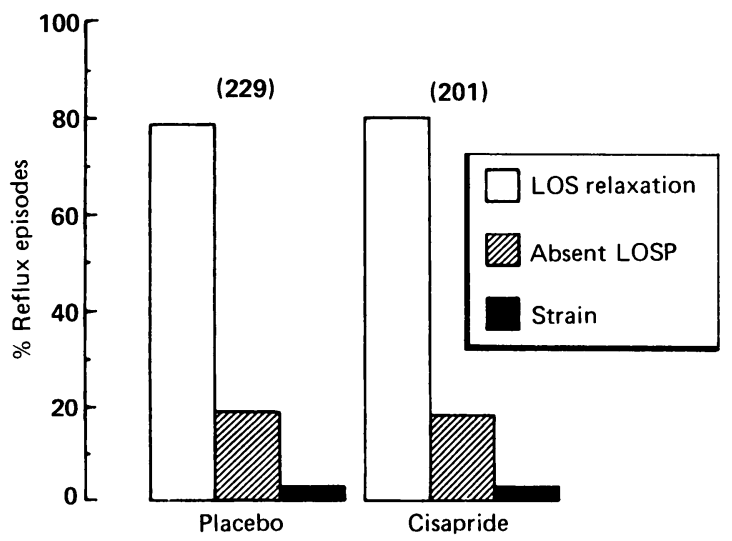

Fig. 6 Effect of cisapride on the mechanisms underlying gastro-oesophageal reflux. Each bar represents the proportion of the total number of reflux episodes. Numbers in parentheses indicate the total number of reflux episodes. 
Table Oesophageal peristalsis

\begin{tabular}{|c|c|c|}
\hline & \multicolumn{2}{|l|}{ Treatment } \\
\hline & Placebo & Cisapride \\
\hline \multicolumn{3}{|c|}{ Peristaltic amplitude $(\mathrm{mmHg})$} \\
\hline Water swallows & $47 \cdot 2(4 \cdot 4)$ & $48 \cdot 9(4 \cdot 3)$ \\
\hline \multicolumn{3}{|l|}{ Peristaltic success (\%) } \\
\hline Water swallows & $82 \cdot 0(0 \cdot 4)$ & $87 \cdot 5(2 \cdot 5)$ \\
\hline Spontaneous swallows & $78.7(0.4)$ & $74 \cdot 2(5 \cdot 3)$ \\
\hline
\end{tabular}

Data expressed as mean (SE) values for postprandial period.

differences existed between cisapride and placebo treatments, or between preprandial and postprandial values.

The trough plasma cisapride level on the morning of the cisapride study was $48 \cdot 1(5 \cdot 0)(\mathrm{SE}) \mathrm{ng} / \mathrm{ml}$. The plasma level rose significantly $(p<0.01)$ after administration of cisapride (peak plasma level $75.9(6.9) \mathrm{ng} / \mathrm{ml})$ and remained raised for the remainder of the study period. Plasma cisapride concentrations were undetectable $(<2 \mathrm{ng} / \mathrm{ml})$ on the placebo study day.

\section{Discussion}

The stimulating effect of cisapride on basal lower oesophageal sphincter pressure ${ }^{5-4}$ has prompted the suggestion that it may have a role in the treatment of gastro-oesophageal reflux disease. In the present study we evaluated the effect of oral cisapride on postprandial oesophageal $\mathrm{pH}$ and motor function in patients with symptomatic reflux. Cisapride enhanced oesophageal acid clearance but had no significant effect on the duration of oesophageal acid exposure, the rate of reflux episodes, or oesophageal motility.

Our findings of a significant improvement in acid clearance supports those of previous studies, ${ }^{1,-16}$ in which a reduction in the durations of individual reflux episodes and the longest reflux episodes has been a consistent finding. In two studies, the improvement in acid clearance was judged to be the principal factor underlying a reduction in oesophageal acid exposure..$^{1314}$

We have found no evidence that the improvement in acid clearance resulted from any improvement in peristaltic function as peristaltic amplitude and success were unchanged. Previous studies have shown that cisapride increases peristaltic amplitude only modestly and only when given intravenously ${ }^{57-9}$ Effects on peristaltic success have not previously been assessed. Such assessment, however, is relevant because Kahrilas and coworkers have shown that abnormal oesophageal peristalsis seen in many patients with reflux disease impairs volume clear- ance. ${ }^{17}$ Cisapride has been shown to improve oesophageal emptying of solids in patients with diabetes mellitus $^{15}$ and slceroderma, ${ }^{14}$ but the mechanisms underlying this effect have not been defined. Possible explanations for the improvement in acid clearance that we observed include a reduction in the volume of refluxate with each reflux episode, or an increase in salivary flow as a result of cholinergic stimulation leading to enhanced acid neutralisation. These hypotheses, however, are untested.

The failure of cisapride to decrease oesophageal acid exposure or the rate of reflux episodes contrasts with the findings of previous studies in children $n^{131516211}$ in which consistent reductions in both these parameters have been observed. In adults, however, the effect on the rate of reflux episodes has been inconsistent. ${ }^{1+21}$ There are several possible explanations. First, the dose used in our study, when adjusted for body weight was approximately half that used in children, although similar to that used in previous studies in adults. Pharmacological studies suggest that in adults at least a $20 \mathrm{mg}$ oral dose is needed to increase lower oesophageal sphincter pressure significantly. ${ }^{*}$ Second, the failure to achieve significance may have resulted from a type II error $(B>0 \cdot 8)$. Third, we studied our patients in the postprandial period. Other studies, in which cisapride reduced acid exposure and reflux rate, were done over much longer periods including during sleep. In only one study, in children, was the immediate two hour postprandial period analysed. ${ }^{16}$ In the remaining studies it is not possible to determine if the effect was evident for the postprandial or the fasting periods or both. The lower oesophageal sphincter appears to be less responsive to the motor stimulating effects of cisapride in the fed state when compared with the fasting state, "possibly because excitatory neural influences that are acting on the lower oesophageal sphincter during the migrating motor complex cycle 23 are less intense or absent. We did not observe any significant effect of cisapride on basal lower oesophageal sphincter pressure. This finding may be partly attributed to the route and timing of administration of the drug. At the dose tested, $10 \mathrm{mg}$, oral administration has, in recent studies, resulted in negligible ${ }^{\gamma}$ or $\mathrm{no}^{*}$ increase in lower oesophageal sphincter presure, and consistent results have been achieved only with intravenous administration. ${ }^{509}$

In this study we confirmed previous findings 1224 that the majority of reflux episodes occur during transient lower oesophageal sphincter relaxations. Our data indicate that cisapride did not alter the rate of transient lower oesophageal sphincter relaxations associated with reflux. Less than $20 \%$ of episodes occurred because of defective basal lower oesophageal sphincter pressure. Even if this portion of reflux 
episodes could be eliminated by raising basal lower oesophageal sphincter pressure with prokinetic agents such as cisapride, this effect would have only a limited impact on total gastro-oesophageal reflux. Thus focussing therapy on the stimulation of lower oesophageal sphincter contraction may not be an optimal strategy for the control of reflux. Rather, therapy would be better directed towards control of transient lower oesophageal sphincter relaxations.

Previous studies have relied on overnight or 24 hour ambulatory oesophageal $\mathrm{pH}$ monitoring to assess the efficacy of prokinetic agents on gastrooesophageal reflux. Such methods, however, suffer from inherent inconsistencies in experimental conditions that are difficult to standardise from day to day or among subjects. ${ }^{25}{ }^{26}$ In the present study we adopted a highly standardised approach, monitoring oesophageal motility and $\mathrm{pH}$ concurrently over the postprandial period using the same meal and a standardised body position. We believe that this approach offers distinct advantages over ambulatory $\mathrm{pH}$ monitoring. First, the experimental conditions can be more easily controlled, and standardised not only among subjects within studies, but also between studies in different centres. Second, recent studies have consistently found that the majority of reflux episodes occur during the day after meals,,$^{27}$ and postprandial reflux appears to be more closely related to oesophagitis than is nocturnal reflux..$^{2 \times}$ Third, and most importantly, concurrent monitoring of oesophageal motility allows the assessment of the effects of these agents on the motor events underlying gastrooesophageal reflux.

In summary, cisapride $10 \mathrm{mg}$ po, had no significant effect on postprandial gastro-oesophageal reflux or oesophageal motility although acid clearance was improved. These findings would suggest that cisapride, at least at the dosage tested, would be unlikely to be of major benefit in the control of troublesome postprandial gastro-oesophageal reflux. Recent studies, however, have shown that cisapride improves symptoms, and heals oesophagiti ${ }^{2024-31}$ with an efficacy similar to that of ranitidine,,$^{32}$ and is an effective adjunct to cimetidine in patients with severe oesophagitis. ${ }^{33}$ The mechanism(s) underlying these clinical effects are not completely clear but may involve a reduction in nocturnal acid exposure, an effect not tested for in the present study.

\section{References}

1 Schuurkes JAJ, Akkermans LMA, van Neuten JM. Stimulating effect of cisapride on antroduodenal motility in the conscious dog. In: Roman C, ed. Gastrointestinal motility. Lancaster: MTP Press, 1984: 95-102.
2 van Neuten JM, van Daele PGH, Reyntjens A, Janssen PAJ, Schuurkes JAJ. Gastrointestinal motility stimulating properties of cisapride, a non-antidopaminergic noncholinergic compound. In: Roman C, ed. Gastrointestinal motility. Lancaster: MTP Press. 1984: 513-20.

3 Schuurkes JAJ, van Neuten JM, van Dacle PGH, Reyntjens A, Janssen PAJ. Motor stimulating propertics of cisapride on isolated gastrointestinal preparation in the guinea pig. J Pharmacol Exp Ther 1984: 234: 77.583.

4 Pfeuffer-Fricderich I, Kilbinger H. Facilitation and inhibition by 5-hydroxytryptamine and R51619 of acetylcholine release from guinea-pig myenteric neurons. In: Roman C, ed. Gastrointestinal motility. Lancaster: MTP Press, 1984: 527-34.

5 Corrazziari E. Scopinaro F, Bontempo I, et al. Effect of R51619 on distal oesophageal motor activity and gastric emptying. Ital J Gastroenterol 1983; 15: 185-6.

6 Smout AJPM, Bogaard JW, Grode AC. Ten Thije OJ, Akkermans LMA. Wittebol P. Effects of cisapride, a new gastrointestinal prokinetic substance, on interdigestive and post-prandial motor activity of the distal ocsophagus in man. Gut 1985; 26: 246-57.

7 Wallin L, Kruse-Andersen S, Madsen T, Bocsby S. Effect of cisapride on the gastro-oesophageal function in normal human subjects. Digestion 1987; 37: 160-5.

8 Gilbert RJ, Dodds WJ, Kahrilas PJ, Hogan WJ, Lipman S. Effect of cisapride; a new prokinetic agent, on csophagcal motor function. Dig Dis Sci 1987; 32: $1331-6$.

9 Ceccatelli P, Janssens J, Vantrappen G, Cucchiara S. Cisapride restores the decreased lower oesophageal sphincter pressure in reflux patients. Gut 1988; 29: 6315 .

10) Ismail-Bergi F, Horton PF, Pope CE II. Histologic consequences of gastroesophageal reflux in man. Gastroenterology 1970; 58: 163-74.

11 Dent J. A new technique for continuous sphincter measurement. Gastroenterology 1976; 71: 213-7.

12 Dent J, Dodds WJ, Freidman RH, et al. Mechanisms of gastroesophageal reflux in recumbent asymptomatic subjects. J Clin Invest 1980; 65: 256-67.

13 Saye ZN, Furget PPL, Geubelle F. Effect of cisapride on gastroesophageal reflux in children with chronic bronchopulmonary disease: a double-blind crossover pH monitoring study. Pediatr Pulmonol 1987; 3: 8-12.

14 Collins BJ, Spence RAJ, Ferguson R, Laird J, Love AHG. Cisapride: influence on oesophageal and gastric emptying and gastro-ocsophageal reflux in patients with reflux oesophagitis. Hepatogastroenterology 1987; 34: $113-6$.

15 Rode H, Stunden RJ, Millar AJW, Cywes S. Esophageal $\mathrm{pH}$ assessment of gastrocsophageal reflux in 18 patients and the effect of two prokinetic agents, cisapride and metoclopramide. J Pediatr Surg 1987; 22: 931-4.

16 Vandenplas Y, Deneyer NN, Verlinden M, Acrts T, Saare L. Gastroesophageal reflux incidence and respiratory dysfunction during sleep in infants: treatment with cisapride. J Pediatr Gastroenterol Nutr. [In press.]

17 Kahrilas PJ, Dodds WJ, Hogan WJ. Effect of peristaltic dysfunction on esophageal volume clearance. Gastroenterology 1988; 94: 73-80. 
18 Horowitz M, Maddox A, Harding PE, et al. Effect of cisapride on gastric and esophageal emptying in insulindependent diabetes mellitus. Gastroenterology 1987; 92: 1899-907.

19 Horowitz M, Maddern GJ, Maddox A, et al. Effects of cisapride on gastric and esophageal emptying in progressive systemic sclerosis. Gastroenterology 1987; 93: 311-5.

20 Cucchiara S, Staiano A. Capozzi C, et al. Cisapride for gastro-ocsophageal reflux and peptic oesophagitis. Arch Dis Child 1987; 62: 454-7.

21 Weiser H, Holscher A, Zimmermann T. Effects of cisapride and metoclopramide on the lower esophageal motility. A pressure and $\mathrm{pH}$-metric study. Digestion 1986; 34: 142 .

22 Dent J, Dodds WJ, Sekiguchi T, Hogan WJ, Arndorfer RC. Interdigestive phasic contraction of the human lower esophageal sphincter. Gastroenterology 1983; 84: 453-60.

23 Holloway RH, Blank EL, Takahashi I, Dodds WJ, Hogan WJ, Dent J. Variability of lower esophageal sphincter pressure in the fasted unanesthetised opossum. Am J Physiol 1985; 248: G398-G406.

24 Dodds WJ, Dent J, Hogan WJ, et al. Mechanisms of gastro-esophageal reflux in patients with reflux esophagitis. N Engl J Med 1982; 307: 1547-52.

25 Wiener GJ, Morgan TW, Copper JE, et al. Ambulatory 24 hour esophageal $\mathrm{pH}$ monitoring: is it a reproducible test for gastroesophageal reflux (GER)? [Abstract.] Gastroenterology 1987; 92: 1695.

26 Shaker R, Helm JF, Dodds WJ, Hogan WJ. Revelations about ambulatory esophageal $\mathrm{pH}$ monitoring. [Abstract.] Gastroenterology 1988; 94: A421.

27 DeCaestecker JS, Blackwell JN, Pryde A, Heading RC. Daytime gastro-oesophageal reflux is important in oesophagitis. Gut 1987; 28: 519-26.

28 Gudmundsson K, Johnsson F. Joelsson B. The time pattern of gastro-ocsophageal reflux. Scand J Gastroenterol 1988; 23: 75-9.

29 Nicolaidis CL, Kehagioglou K, Mantzaris G, et al. Therapeutic effect of two dosages of cisapride in controlling chronic reflux symptoms in esophagitis paticnts. Curr Ther Res 1987; 42: 1059-65.

30 Lepoutre L, Vanderlinden I, Bollen G, et al. Controlled study of cisapride in the treatment of grade II and III oesophagitis. Gastroenterology 1987; 92: 1501.

31 Baldi F. Cisapride compared to placebo in healing reflux esophagitis. A multicentre double-blind trial. J Clin Gastroenterol 1988; 10: 614-8.

32 Janisch HD, Huttemann W, Bouzo MH. Cisapride versus ranitidine in the treatment of reflux esophagitis. Hepatogastroenterology 1988; 35: 125-70.

33 Galmiche JP, Brandstatter G, Evreux M, et al. Combined therapy with cisapride and cimetidine in severe reflux oesophagitis: a double-blind controlled trial. Gut 1988; 29: $675-81$. 